\title{
Public Participation and Trade-offs in Flood Risk Mitigation: Evidence from Two Case
}

\section{Studies in the Alps}

\author{
Anna Scolobig, Luigi Pellizzoni, and Chiara Bianchizza \\ Nature and Culture 11(1), Spring 2016 \\ Pre-print version
}

\begin{abstract}
There is an increasing demand for improvement of the quality of decisions about flood risk mitigation by fostering public participation in decision-making. However, the extent and way in which formalized participation guarantees good outcomes is still a matter of discussion. This article analyzes different approaches to decision-making for flood risk mitigation by comparing two experiences in the Italian Alps. In Vipiteno-Sterzing, decisions were made by involving citizens in a structured participatory process. In Malborghetto-Valbruna, a formally technocratic (yet substantially inclusive) approach was adopted after the flood that affected the municipality in 2003. Our results critically review the perspective that structured participation is always something "good" In this regard, the way relevant trade-offs between public and private goods were acknowledged and dealt with turned out to be crucial. At the same time, effective participation is closely related to citizens' actual engagement, institutional responsiveness to residents' needs and expectations, and the capacity to harmonize different views and types of knowledge in the development of risk mitigation options. Policy context, choice of approach and quality of outcomes appear as "nested" issues. Further research is needed in order to assess different experiences of decision-making and to set robust conditions for better outcomes in public participation.
\end{abstract}

\section{Keywords}

alpine hazards, citizen engagement, flood risk, mitigation trade-offs, participatory processes 


\section{Introduction}

In the last decades, European countries have witnessed an increase in damages to people and property due to weather-related events (e.g., windstorms, hailstorms, floods, extreme temperatures, and severe storms; see WMO 2013). In the Alpine region, natural hazards constitute major threats to human life and activities, settlements and economic areas, transport routes, supply lines and other infrastructure (compare, e.g., Bianchizza et al. 2011). Among the events resulting in the largest overall financial losses in Europe in the decade 1998-2009, the most severe is represented by the floods that hit Italian, French, and Swiss Alps in the year 2000 (€12 billion), followed by those in central Europe in 2002 (€20 billion), (EEA 2010).

Looking at these figures, it is evident that Europe is in fact severely threatened by an increase in the occurrence of extreme events, triggered by both natural and anthropogenic factors (IPCC 2012; WMO 2013). From a physical perspective, when discussing an increase in risk exposure in the Alpine region reference has to be made to climatic changes and particularly to changes in precipitation patterns, temperatures, and extreme events. There is evidence that climate change contributes to increasing the frequency and intensity of weatherrelated hazards in Europe. It is estimated that the effects of climate change could intensify in the future (EEA 2010; IPCC 2012).

To deal effectively with these issues it is relevant to take into account not only technical aspects, but also the social, economic, political and cultural sides of risk mitigation. The severity of the impacts of natural hazards rests on pre-existing conditions of vulnerability—not only of buildings and infrastructures, but also of people, social networks and institutions (Kuhlicke and Steinführer 2010). In this sense, European societies need to enhance not only technical but also social capacities as a means to anticipate, cope with, and recover from the impact of natural hazards and to reduce vulnerability (Blaikie et al. 1994). 
Social capacity building should be considered a long-term process that fosters mutual and continuous learning among the different stakeholders involved in risk management (Kuhlicke et al. 2012). The involvement of stakeholders in decision-making is generally regarded as key to increasing social capacity at the local level and fostering a learning process in decisionmaking. This article analyzes implications, potentials, and limitations of participation in the context of decisions concerning flood risk mitigation. It draws on two case studies: the Italian municipalities of Vipiteno-Sterzing (region of Trentino Alto Adige, northern Italy) and Malborghetto-Valbruna (region of Friuli Venezia Giulia, northeastern Italy), both located in alpine valleys affected by high hydro-geological risk (flash floods, debris flows, landslides, avalanches, etc.). They can be considered examples of two different decision-making approaches to flood risk mitigation. In Vipiteno-Sterzing, a bottom-up or "participatory" decision process was applied: risk mitigation measures were adopted by submitting different options to local citizens and by involving them in making the decision. In MalborghettoValbruna, an "interventionist" (top-down or "technocratic") approach was used after a flood event that affected the municipality in the year 2003 .

A comparison of these two cases allows for a critical view of the perspectivewidespread in deliberative democracy scholarship (Pellizzoni 2013) — that formalized participation generally improves policy quality and legitimacy. Results show how participatory decisions can be made even when no formal involvement process takes place (i.e., within a top down or technocratic decision setting), while a formal participatory process may lead to decisional paralysis. In other words, it may well be that, thanks to favorable social factors, informal participatory processes are more effective than structured forms of participation. In this regard, the way in which relevant trade-offs are acknowledged and dealt with as well as the local policy context are crucial. 
It must be stressed from the outset that our study has an exploratory character, which entails limits in terms of robustness of the inferences made. As we shall explain, we seek to connect policy contexts and processes, with specific reference to more or less formalized participatory designs and their effectiveness in dealing with emergent trade-offs in decision making. In spite of the significant amount of data gathered on these cases, we do not pretend to give such connections a causal character. Yet, despite these limitations, we believe this exploratory exercise is worthwhile, especially considering the scarcity of empirical evidence in the problem area we are addressing.

The following two sections summarize the theoretical and methodological background of the study. We subsequently describe the decision-making approaches adopted in the two cases and identify key trade-offs between public and private interests, which represented the main sources of conflict in the decision processes under study. We explore how these tradeoffs have been dealt with, dwelling on the role played by the policy context in affecting the degree, form, and effectiveness of citizen engagement. The last section summarizes the main insights provided by the study.

\section{Theoretical Background}

The severe consequences of weather-related hazards point to the increasing importance of effective risk reduction. ${ }^{1}$ In this context, measures of a non-structural nature such as warning systems, risk communication, training and simulation exercises aimed at improving individual and community preparedness are gaining importance (Johnson and Priest 2008; Green et al. 2013). A common requirement of these measures is a consistent involvement of civil society to build social capacities and reduce vulnerability (Johnson and Priest 2008; Dieperink et al. 2013). This implies that non-governmental actors should also be involved in risk reduction. This involvement, it is generally maintained, should be based on a constant flow of 
information and dialogue on flood risk, emergency planning and mitigation options (DEFRA 2005, 2008; Merz et al. 2010; Butler and Pidgeon 2011; Kuhlicke and Steinführer 2010). At the level of policy practices, it has been observed that in many European countries governments tend to keep the power of defining risk reduction policies while at the same time seeking to shift economic costs and responsibilities for implementation to other social actors (Kuhlicke et al. 2012). Those at risk—residents, industrial and commercial businesses, farms, infrastructure managers, etc.- - are gradually transformed into active participants in multi-scale risk governance networks, as they are encouraged, or even required, to take increasing responsibility for their personal and community protection (Walker et al. 2010; Bianchizza et al. 2011).

The increased relevance of stakeholder participation is reflected in several policy documents. For example, the Hyogo framework ${ }^{2} 2005-2015$ lists among its priorities the need for inclusion of citizens in natural hazard management. Moreover, the involvement of local stakeholders in decision-making has often emerged as a legislative requirement. For example, several European Directives (such as the Water Framework Directive 2000/60/EC, EC 2000 and the Floods Directive 2007/60/EC, EC 2007) and their implementing measures on the national and regional scale focus on the creation of actual opportunities for population involvement in natural hazards management decisions. Strengthening participation at the level of both territorial planning and hazard prevention and mitigation is therefore an issue with clear relevance for both existing and prospective policy and legislative efforts and programs.

Before focusing on participation in flood risk management, it is worth exploring briefly the range of meanings the word "participation" takes and the basis upon which its diffusion rests. When speaking of participation in general, one can mean anything that ranges from mere receptiveness to information to the self-mobilization of citizens (De Marchi 2003). Thus, participation could be the result of a top-down attempt to spread information about 
certain decisions concerning public affairs, or its opposite movement, namely bottom-up initiatives of citizens that seek to be actively involved in decision-making — with any combination of these two polar options in between. Actual participation is, in fact, typically located between the two opposite polarities of the "Arnstein ladder" (Arnstein 1969).

It is important, however, to mention that the current success of participation in public policy-making — not limited to but significantly diffused in the environment and land-use fields - does not so much refer to spontaneous, informal processes as to structured forms of involvement promoted and organized by public authorities to address collective issues (Pellizzoni 2010). The spread of these forms of participation builds on certain assumptions. On one side, the cognitive limits of one-way communication, of the "deficit model" in the public understanding of science and of expert-based decision-making, have emerged with growing clarity, fostering a shift toward dialogue and two-way exchange (Wynne 1992; Stirling 2005). On the other side, deliberation is seen as a reply to the crisis of representative democracy and the administrative state, offering the opportunity for a (re)intensification of people's involvement in, and influence on, policy making, in a context of growing inefficiency of traditional institutions and approaches. In short, the assumption is that, if properly understood and applied, participation implies more democratic decision-making processes, greater social cohesion, improved policy quality and effectiveness, and, in some cases, even conflict resolution (Pellizzoni 2013). Participation can bring new options to light, allowing local concerns to be taken into account and delineation of terrain for agreement based on consensus or compromise. Another expected benefit is that these processes ensure greater fairness in decision making in a context where people are increasingly demanding more transparency from their risk management institutions (Renn 2008; Rowe and Frewer 2000; Dryzek 2000). Even the way these processes are designed can strengthen institutional credibility. From the perspective of a decision maker, a participatory process can help not 
only to understand local stakeholder needs and expectations but also to share responsibility for the decisions undertaken (Scolobig et al. 2011).

However, participation is not a panacea and there are many problematic issues related to the implementation of these processes, beginning with the criteria for inclusion in the process, which entails drawing boundaries in regard to the instances, groups, knowledge, values, and behaviors relevant to the topic at stake. Another major problem is related to how process outcomes can be legitimized within the broader policy arena, and namely by those groups that have not been involved as well as interests and concerns that have not been directly or explicitly taken into consideration. A number of methodological issues are still under debate, such as how to choose the appropriate participatory model according to the features of the issue and the goals pursued, how to make it flexible enough to adapt to key topics emerging along the way, how to communicate complex scientific information and knowledge and so on (for a review of models and debates see, for example, Fishkin and Laslett 2003; Gastil and Levine 2005; Parkinson 2006). In other words, if managed improperly, participatory processes may lead to inefficiencies, stabilize existing power distributions, slow decision making, foster conflicts and immobilize institutions (e.g., Lofstedt 2004). These types of outcomes frequently stem from an overambitious objective to reach a general consensus on a shared solution (Scolobig et al. 2011).

In sum, there are good reasons for promoting participation whenever public resources and public values are at stake (McDaniels et al. 1999), yet there are also a number of pitfalls that may undermine the securing of wide and effective public engagement (Stirling 2005).

Research focused on participatory processes about flood risk management, the specific issue of this article, is relatively scarce. The number of cases has grown in the last decade, yet to our knowledge there is a lack of studies aimed at a systematically assessing past experiences. Available evidence, particularly in the water management sector, suggests that 
the presence of certain problematic aspects can hinder effective participation. These include, for example, difficulties in negotiation, lack of transparency regarding the interests and values at stake, poor facilitation, power imbalances, lack of trust, persistence of biased preferences, poor impact on decisions, etc. (e.g., Aldred and Jacobs 2000; Messner et al. 2006; Junker et al. 2007; Becu et al. 2008; Kallis et al. 2009; Paneque Salgado et al. 2009).

A key issue for flood risk seems to be the way relevant trade-offs are acknowledged and dealt with — namely, those related to diverse possible approaches to risk mitigation, which impinge in different ways on local interests, values, and power distribution. In other words, public deliberation on risk mitigation typically takes the shape of a zero-sum game, whereas the success of a participatory process often lies in its capacity to single out previously unacknowledged win-win solutions (Pellizzoni 2010). When trade-offs are not recognized and addressed, they are likely to hinder effective communication and collaboration among stakeholders, causing conflicts, blocks, delays or failures (Beatley 1989, 1999; Burby 1998; Cialdini 2001; Gregory 2002; Godschalk et al. 2003; Couzin et al. 2011; Scolobig et al. 2011; Carr et al. 2012). Indeed, trade-offs lead to either contradictory conclusions or incompatible choices, mostly because different stakeholders apply different criteria to the evaluation of a given situation.

Trade-offs in flood risk mitigation decisions may be related to different understandings of safety and risk issues, mismatching considerations of equity issues (e.g., concerning risk distribution), different views about priorities (e.g., economic growth versus collective safety), contrasting land use designations, divergent attributions of responsibility for safety and flood mitigation, etc. (see also De Marchi and Scolobig 2008; Penning-Rowsell and Pardoe 2012).

One factor that complicates the picture is uncertainty related to future events. Thus a conflict typically arises between certain, immediate loss of some good (e.g., land) and alleged protection against an uncertain event that might occur in the future. This is particularly 
relevant in mountainous areas, where land is scarce and thus has a high value. Prioritizing the designation of use is thus crucial; often the possibility of using land for a range of economic activities (agriculture, construction, etc.) is seen as definitely more tempting than preserving it for protection purposes.

As outlined above, our study focuses on the way comparable issues, conflicts and trade-offs related to flood risk mitigation have been addressed within different decisionmaking settings.

\section{Methodology}

Our research, carried out within the EC-funded projects FLOODsite and CapHaz-Net (see Acknowledgements), was undertaken in the upper Adige/Sarca and Tagliamento river basins - both subject to flash flooding and debris flows. This article reports results and findings obtained through a combination of different techniques of data gathering and analysis. A case study approach was adopted, where few units are investigated in depth in order to better grasp the inherent complexity of the social phenomenon under study (Eckstein 1989; Yin 1989). ${ }^{3}$

The research design foresaw the combination of different techniques. Participant observation was used in different phases. We visited the research sites several times and spent time there speaking with residents, local authorities, fire brigade members, etc., to build an idea of the structural and cultural traits of the communities and to collect information about flood risk mitigation decisions (compare Pike 1967; Goodenough 1970; Harris 1980). Data gathering included existing information, such as census data and provincial archives; three focus groups with officers from census services and agencies in charge of civil protection, risk prevention, water resources, hydrology; eighteen semi-structured interviews with qualified informants (i.e., people who, due to their status, role, or experience, had a deep knowledge of 
the topic under investigation and/or its social context) including local authorities, civil servants, community leaders, politicians, scientific and technical experts, members of nongovernmental organizations; a standardized questionnaire submitted to a quota sample of 102 inhabitants in Malborghetto-Valbruna and 186 in Vipiteno-Sterzing; a workshop involving thirty-five participants, among which eleven were qualified informants on the case studies, and a post-workshop feedback round with participants.

The specific purpose of the focus groups was to collect views on the communities' capacity to respond to and recover from flood events. Moreover we asked participants to identify key aspects of and problems encountered during the decision-making processes about risk mitigation. The topics discussed included individual and community risk awareness and preparedness, local and expert knowledge about risk, main trade-offs and conflicts related to risk mitigation options, etc.

On the basis of the findings from the first two phases just described, we constructed a questionnaire that was pretested with twenty-two pilot interviews in Malborghetto-Valbruna. The final version consisted of 147 prestructured questions (some of which were grouped into batteries) plus another twenty open-ended ones. Residents' opinions, attitudes, and behaviors were recorded with regard to several aspects of flood risk management, from prevention to recovery issues.

The questionnaire was submitted face-to-face to a sample of residents by trained interviewers. We opted for a sample based on quotas of residents selected according to gender, age, education and level of risk exposure (high, medium, low) (see also De Marchi et al. 2007). Finally, in the stakeholder workshop, participants were asked to reanalyze risk mitigation decision processes. Based on previous results, some aspects were identified as key to the analysis of the cases, namely: citizens' risk perception and awareness (as operationalized and measured in the questionnaire surveys); risk communication among the 
involved parties (local people, authorities, civil protection service etc.); knowledge about risk issues (territory, risk, suitable behaviors in case of flood; lay-local versus expert views); relevant networks at the community level; involvement of citizens in the decision-making process; and citizens' trust in local authorities, operators of civil protection, experts and features of decision-making processes.

In the following section, due to limits of space, we will not dwell in detail on the results of the various phases of the field research (for comprehensive reports see De Marchi et al. 2007; Bianchizza et al. 2011). We instead extract from them what is especially relevant to our topic.

\section{Decision-Making Approaches}

In this section we present the two cases, focusing on their social and territorial characteristics and the salient features of the respective decision processes, including issues that played a role in the choice of mitigation measures. In both cases mitigation works have been completed or planned yet following different approaches according to the responses of residents and involvement of local authorities. As previously noted, in Vipiteno-Sterzing, a "participatory" approach (i.e., leaning toward a bottom-up/inclusive decision process) was applied: decisions about risk mitigation measures were made by submitting different options to local citizens and by involving them in the decision-making. In Malborghetto-Valbruna, an "interventionist" approach (i.e., leaning toward a top-down/technocratic decision process) was used to make decisions after a flood event that affected the municipality in the year 2003. On closer inspection, however, the processes turned out to be more complex, and "participation" can be found also where in principle it should be absent. 


\section{Vipiteno-Sterzing}

Vipiteno-Sterzing is a municipality of the autonomous province of Bolzano/Bozen, in the region of Trentino Alto Adige/Südtirol in Northern Italy. The province borders Austria (provinces of Tyrol and Salzburg) to the east and north and Switzerland (canton of Grisons) to the west. The municipality $(6,306$ inhabitants in its ten hamlets, per the 2010 census) is crossed by the river Isarco/Eisack.

The area of Vipiteno-Sterzing has been periodically affected by floods of the Isarco river and its tributaries. Experts stress that the flood risk is very high and the town has been flooded frequently between 1965 and 1998. However, according to local authorities, the lack of any major consequences and the fact that the last extremely hazardous events took place in 1966 and 1987 has led to the fading of collective memory. As a consequence, the community's perception of risk is rather low.

A project, funded by the European Union's INTERREG IIIB program and called "River Basin Agenda/Agenda Fluviale Alto Isarco," concentrated on the upper part of the Isarco/Eisack and on its two tributaries. The project involved eleven rivers of six alpine states and aimed at promoting transborder cooperation in the management of alpine river basins. The "Forum Alto Isarco" was created in this context as a space for municipalities, local administrations, organizations with interest in economic development, tourism, environment and agriculture, to cooperate with experts in defining guidelines for river management, taking into account flood defense needs, environmental issues, and potential future use of the territory.

After a risk assessment conducted in 2009 , the provincial office for hydraulic works made the realization of mitigation works in Vipiteno-Sterzing a priority. This encouraged the design of different potential solutions that were then presented to the population. Citizens whose land property would be reclaimed for the realization of the flood mitigation plan were, 
unsurprisingly, unhappy with all of the solutions proposed. Thus, a new alternative was designed to meet the requests of the citizens. The new proposal was presented to the community at the end of October 2009. The river bed would be enlarged in certain parts and restricted in others, the embankments would be "naturalized" (concrete embankments removed in favor of more gently sloping banks), and a fluvial park would be created and opened to the public. Again, several landowners whose property would have been expropriated for the realization of these works complained loudly. They claimed that the information about these projects had not been transparent and that the explanations given were too general. Some landowners belonged to the municipal council—and landowners in general have considerable political weight. Hence, expropriations would have been problematic for the administration.

After a discussion on mitigation alternatives within the river management forum, the eventual decision was for a different option. When the fieldwork for this research was performed (2011), however, this option was still under discussion and the residents did not approve the use of land for other purposes (naturalization, fluvial park, town-scaping, etc.). Such orientation emerged in the interviews and the workshops (Bianchizza et al. 2011). This decision process, therefore, had no immediate implementation but brought forward previously hidden conflicts. The latter, however, were not directly addressed during the process.

In March 2012, mitigation works in the municipality were restarted, with partial lowering of the river banks and enforcement of the embankment. After three years since the end of the participatory process, mitigation works were not yet completed and in August 2012 the river Isarco flooded the plain, causing the municipality to call a state of emergency (Calzolari 2012).

In conclusion, we can identify some salient features of the decision-making process in Vipiteno-Sterzing. The Evaluation of the River Basin Agenda was a unique opportunity for 
the involvement of stakeholders in a forum of discussion and decision-making that took into account different economic, ecological, social, and infrastructural concerns. During the process there was a strong distinction between immediate versus prospective losses and uncertain events. The former dominated the discussion. As a consequence, the decisionmaking was affected more by economic and political elements than by safety requirements. Even if people agreed on the need to increase safety in general, their attitude changed when their individual interests were affected by the implied decisions. In turn, local authorities had the power to expropriate land, but they would incur considerable problems, due to the opposition of politically influential landowners. As a result, suboptimal safety measures were adopted.

Finally, the participatory process did not offer a possibility for participants to elaborate on mitigation measures, but only to choose among given options. Residents were involved only at a later stage of decision-making, which caused them to be disappointed and to mistrust the local authorities.

\section{Malborghetto-Valbruna}

Malborghetto-Valbruna is a small municipality (1,036 inhabitants in six hamlets) in the mountainous area of the region Friuli Venezia Giulia (northeastern Italy). The municipality is located in an alpine valley bordering Slovenia and Austria, at the confluence of the river Fella with its tributaries, the streams Uque and Malborghetto. The municipality is exposed to hydro-geological hazards such as flash floods, debris flow, landslides, etc.

On 29 August 2003, a flash flood hit the municipality, causing severe damage. Two residents died while trying to save their properties and approximately 600 residents had to be evacuated. Extensive material damage ( $€ 190$ million) has been reported. 
Some months after the event, a Flood Office, coordinated by the regional authorities, was set up in the municipality. Its duties included the organization of compensation procedures for people affected by the flood and technical assistance to other municipal departments to speed up the recovery process. Risk mitigation decisions had to be taken very quickly in order to be integrated in the reconstruction process. No formal participatory process took place. The mayor and the leading political party together with Civil Protection engineers proposed the construction of new protection works, while the political opposition at the municipal level made a case for the inclusion of local and traditional knowledge to arrive at more informed decisions, grounded in a deeper understanding of the territory and its transformations. Citizens with no specific political affiliation, but living in one of the most endangered areas (a neighborhood named Cucco), constituted a Safety Committee asking for more protection against hydro-geological risk through structural mitigation measures and starting a dialogue with the mayor and other local politicians. Some requests from the Committee were incorporated in the final risk mitigation project. This included a major infrastructure protection work constructed behind the town hall, several works along the streams and in the upper mountain area, reinforcement of the stream banks, and relocation of some houses. It is worth noting that environmentalist groups asked for a "renaturalization" of the old river bed, yet many local residents disagreed, regarding this approach as unnecessary, burdensome (requiring the relocation of some people), and alien to local traditions of territorial maintenance. On the contrary, voluntary fire brigades expressed their perplexity on the implementation of new structural measures, as they considered them a potential source of danger during extreme events. So the framework of decision-making was anything but consensual. Yet a generally accepted compromise was achieved and a risk mitigation project was completed. This success is due, to a remarkable extent, to the mayor's mediating role and his personal assumption of responsibility for decisions, legitimized by the expertise of the 
regional Civil Protection. Although some issues remain open (for example, who is formally in charge of the maintenance of mitigation works is not yet clear, although ordinary maintenance is concretely carried out by the municipality), when another major flood hit the valley in 2009 the mitigation works proved effective in reducing the risk exposure of the hamlets.

Here we can identify several salient features in the Malborghetto-Valbruna decisionmaking process. Negotiation and constant communication began immediately after the event between the mayor and the different stakeholders involved: the political opposition at municipal level, which advocated local knowledge; the Safety Committee, which asked for structural mitigation measures; and environmentalist groups, who desired a "renaturalization" of the old river bed. In this context, the mediating role of the mayor was made credible thanks to his clear assumption of responsibility. As a result, some requests of the Safety Committee and of the political opposition were included in the final risk mitigation plan: mitigation works with a strong infrastructural component were completed, demonstrating their effectiveness during subsequent flooding events.

\section{Trade-offs Between Public Safety and Private Interests}

As previously noted, this study assumes that, in devising measures for risk mitigation, tradeoffs almost inevitably emerge and that, if not properly addressed, are likely to hinder effective communication and collaboration among stakeholders, causing conflicts, delays or failures in the decision-making. Understanding how key trade-offs have been dealt with in the two cases was a primary goal of our study.

Trade-offs mainly originated from conflicts between public and private interests, or "goods." The relationship between high safety standards and economic/urban development was especially complex and influenced flood risk mitigation decisions in both cases, even if in partially different ways. 
One highly debated issue was the construction of protection works. Generally, building new structural risk mitigation measures reduces risk and as a consequence, the protected area is safer; building restrictions can be removed, and urban/economic development is allowed where it was previously forbidden. However, opposition to structural mitigation works can also be strong, either because of their possible failures or because of the need to expropriate private properties for their construction. As we have seen, in both our cases some individuals were against the construction of protection works, often for different reasons.

In Malborghetto-Valbruna, the fire brigades were afraid of the failure of structural works, which could increase damage in the case of extreme events. They insisted on the importance of residual flood risk (i.e., unavoidable risk that remains despite effective flood prevention and control policies) and emphasized the need to make residents aware of it (Scolobig et al. 2008). In contrast, the Safety Committee asked for higher safety standards through the construction of new structural protection works, following the assumption that "the stronger the protection measures, the safer we are" (as a Committee's member said when interviewed). Questionnaire results actually confirm that protection works increased residents' feeling of safety (we asked respondents about their level of agreement, gauged on a 1-5 point Likert scale, regarding the statement "The protection works give a sensation of safety"; mean value obtained is 4.49), while the cost of such works was a lesser issue considering their expected benefits for the economic development of the community (the statements were "The protection works promote the economic development of the community": mean value is 3.48 ; "The protection works are too expensive compared to the expected benefits": mean value obtained is 1.76: both items gauged on a 1-5 point Likert scale).

The perception of safety seems thus to be strongly related to the presence of structural devices. In Vipiteno-Sterzing, expropriation of private properties for building structural 
devices was instead the main trigger of residents' disagreement with the proposed mitigation option. Questionnaire results help to understand the reasons for residents' skepticism and opposition. When asked about risk mitigation options in an open-ended question, many respondents basically said that developments were allowed in risky areas, to meet individual interests (speculation) and economic constraints (cheaper property allotments) (55.6 percent), as well as a result of scarcity of land and faint memory of past events (20.8 percent). The remaining respondents mentioned geo-morphological structural factors related to risk exposure (22.2 percent) or did not answer (1.4 percent).

These results support the hypothesis that pressure from groups with significant economic stakes on risk issues delayed the entire decision-making process and that the conflict between public and private interests represented a key barrier to finding a suitable solution.

The diverging standpoints on the construction of new protection measures and ultimately toward safety in the two cases are likely to depend on a number of factors, among which the different perceptions about flood risk may play a relevant role. In MalborghettoValbruna, risk awareness was heightened by the destruction caused by the 2003 flood. Hence, safety was arguably valued more than material goods. Questionnaire results show that after the 2003 event the level of awareness of flooding increased consistently together with the perception of future risk. More precisely, before the event one third of respondents (33.3 percent) expected the flood to happen, after the event almost all respondents ( 88.2 percent) expected something similar to happen again.

In Vipiteno-Sterzing, where no floods had occurred for decades, very few respondents assigned a high probability to the occurrence of an event. More precisely, less than one-fifth (18.3 percent) considered the probability of undergoing hydro-geological events to be high (scores 4 or 5, on a 1-5 point Likert scale), a third (33.3 percent) settled on the medium 
position of 3 and about two-fifths of the sample (38.2 percent) considered Vipiteno/Sterzing to have a low probability (scores 1 or 2 ). About a tenth of the sample (10.2 percent) replied with a "don’t know."

However, other factors seem to influence the value attributed to safety. For example, the amount of land to be expropriated for the implementation of structural measures was different in the two cases: in Malborghetto-Valbruna protection works had to be built mostly upstream, while in Vipiteno-Sterzing they had more impact on economically valuable land. In a similar vein, one has to also consider the impact of new protection works on the housing market. When these works are constructed, as noticed, risk levels decrease and building constraints are removed. Decrease in risk levels creates privileged groups of people living in an area defined as safe, while the value of their properties increases. This was one of the main motivations behind the requests for more protection coming from the Safety Committee in Malborghetto-Valbruna and it heavily influenced the decisions. Also, the environmentalists' proposal of a "renaturalization" of the river bed clashed with the interests of private landowners who were unwilling to give up their land for measures — such as river bed enlargement—seen as unnecessary for safety purposes. As already remarked, moreover, the idea of recovering an "original" environment was regarded by many residents as divergent from local styles and traditions of territorial maintenance, allegedly grounded on a "sound relationship between rivers and humankind" (as reported by one interviewee). Moreover the renaturalization would also imply the relocation of certain settlements in hydro-geologically safer areas, yet residents did not want their houses to be moved.

In conclusion, trade-offs between public and private interests represented key challenges in both cases yet they worked in partially different ways according to social and territorial specificities. Interview results in Malborghetto-Valbruna showed that civil protection experts' knowledge, residents' trust in them, and the mediating role of the mayor 
represented key elements in dealing with the trade-offs and in the finalization of the risk mitigation project. On the contrary, the formal participatory approach adopted in VipitenoSterzing was not particularly helpful in addressing trade-offs and conflicts-indeed, the opposite seems the case. To better understand and explain this result that runs contrary to much of the literature on participation and public deliberation (e.g., Fishkin and Laslett 2003; Fung and Wright 2003; Gastil and Levine 2005), our data highlight again the relevance of the social context.

\section{Policy Context and Citizen Engagement}

If we compare Malborghetto-Valbruna and Vipiteno-Sterzing, key differences emerge with regard to policy context and citizens engagement. The first is a small municipality, whose residents have a strong sense of belonging and where there is historically a significant presence of qualified volunteers of civil protection. As shown by questionnaire results, the presence of a local fire brigade and the perceived efficiency of the civil protection service are among the main factors contributing to the residents' feeling of safety. Moreover, residents are actively involved in the everyday management of the territory. They have very good knowledge of their territory, with special reference to logistic-organizational aspects related to emergency management such as escape routes, people in charge of emergency management, behaviors to adopt, etc. This is also due to the fact that most of them took part in the meetings and information initiatives about flood risk mitigation organized after the 2003 event by the local authorities. Furthermore, the effective mediating role of the mayor helped residents to feel recognized as legitimate participants in the decision process, and authorities to be receptive to stakeholder needs and expectations. Thus, a formally "interventionist," top-down process was in practice capable of involving the whole community, which was consulted informally but consistently throughout the reconstruction and mitigation processes. In this 
way residents acknowledged the local authority as representing its constituency by taking the lead in decisions that, while not unanimously supported, were accepted as the result of a democratic consultation and accepted as a suitable compromise. Of course it is difficult to say to what extent the mayor's catalyzing role is due to personal qualities, yet there is little doubt that the small size of the community and the personal acquaintance of residents with their reference authority were important factors in this respect.

The preceding picture does not apply to Vipiteno-Sterzing. This community is much larger and there is a high degree of mobility, with consequent lack of shared knowledge of the territory and lower social cohesion. Most of those surveyed did not feel involved in the overall process of flood risk management and tended to delegate the responsibility for safety to agencies in charge of flood prevention and mitigation. In this context, the attempt to establish democratic decision-making had to rely on the formal organization of a participatory agenda, which ultimately involved people who were neither involved in the everyday management of the territory nor felt recognized in their concerns, since they were asked to work on a range of options as devised by the organizers. The weak link between residents and territorial management, and the former's perceived lack of institutional receptivity to their needs and expectations, led to an exacerbation of pre-existing tensions related to economic and political interests.

In short, actual stakeholders' participation in the decision-making seems to be related to their proper engagement (Pellizzoni 2007; 2010). The Malborghetto-Valbruna case indicates that risk mitigation options can be effectively elaborated by interfacing stakeholder preferences with expert knowledge, rather than by presenting a full-fledged project and then asking for people's feedback. In this sense, despite following a typical structured form of involvement, the process that took place in Vipiteno-Sterzing cannot be regarded as "properly" participatory. In other words, interventionism and community engagement are not 
clean alternatives defined in formal terms, being dependent on the concrete way they are deployed. At the same time, choices are not simply a matter of the authorities' sense of democracy — or political opportunity — but are also related to contextual factors that affect the concrete viability and working of a given option. In this sense, policy context, process options and their outcomes represent "nested" issues in which the room for maneuvering can be tighter than deliberative theory is generally ready to recognize.

\section{Conclusion}

Building on evidence from two case studies, this article aimed at contributing to the debate on public participation in flood risk mitigation. Results offer additional evidence of two connected points often stressed by the literature on participation, namely: that dialogue, or two-way communication, is potentially highly significant for improving the quality and legitimacy of policy-making, however, to express this potential, participatory processes must be carefully targeted to the particular context of application and goals pursued. We have also seen that flood risk mitigation presents characteristics that depend on the configuration that the issue typically takes, as related for example to the history of a place (from the size of the community to the mobility of residents and the record of relevant floods in a recent past) and to the conflict between general interest in safety and particular (usually economic) interests. In this perspective, our study has identified some trade-offs that may easily emerge in decisionmaking and has assessed how such trade-offs have been managed in specific cases.

We reasoned in terms of trade-offs for theoretical and empirical reasons. Theoretically, they produce an intrinsically problematic deliberative setting, giving the participatory process the shape of a zero-sum game. Empirically, trade-offs affected the risk mitigation processes we studied in different ways, and when not directly addressed in public debates impinged negatively on the decision-making. What the cases analyzed show is that the trade-offs 
concerning conflicts of interest—and particularly those regarding conflicts between public and private "goods"- are problematic, not being easily amenable to negotiated solutions. Results indicate that these conflicts can be more difficult to manage in a formal participatory setting than in an informal "interventionist" one, especially when the memory of past events has faded. These trade-offs are certainly not new to decision-making processes. However, the two cases discussed offer some additional insights. While the trade-offs identified are similar, the way in which they were addressed differ substantially, being the result of the different features of the social context, yet simultaneously triggering diverging decisional approaches. In other words, the context of, and approach to, trade-offs are intertwined and vital to determining the degree of success of participation in decision-making.

Directly addressing trade-offs, when this is possible, is beneficial to institutional trust and acceptance of interventions. While in Vipiteno-Sterzing clearly visible (yet never directly addressed) conflicts remained unsolved leading to a solution that meets neither mitigation needs nor civil society desires (embankment enlargement works started only in March 2012), in Malborghetto-Valbruna acceptance has been grounded in a constant dialogue and a pragmatic approach to questions of equity in risk distribution and protection.

The timing of dialogic processes also plays a role in affecting the possibilities of success. In Malborghetto-Valbruna, debate started almost immediately after the flood event, also due to the involvement of the residents directly impacted and who were thus eager to hasten recovery and initiate prevention actions; hence, all issues and views were discussed and debated since the beginning. In Vipiteno-Sterzing, people's risk perception was very low and thus the initial steps in priority definition had to be taken by local authorities. As a consequence, residents found themselves involved only at a later stage — hence their feeling of late involvement and mistrust toward the local authorities. The results of the process clearly 
show that public participation does not per se add to the credibility of institutions, guarantee more fairness in decision making, improve social cohesion or contribute to conflict resolution.

We have acknowledged from the outset the limits of our research and the caution with which inferences from available evidence can be drawn. In this sense further research is needed in order to assess different experiences of decision-making on flood risk mitigation and to set out robust conditions under which public participation may lead to better outcomes. Experiences of public participation in flood risk management are growing at the European level, partially as a result of the implementation of European Directives. This growing relevance of mitigation methods will entail a better understanding of the benefits and limits of past experiences.

With such care and hope in mind, three final remarks can be made. First, in cases where risk perception is low and initiative needs to come from public authorities, it seems important for conflicts of economic/political nature to be addressed directly and as soon as possible. These potential conflicts should be considered before contemplating the option of a participatory process. Recognition of the legitimacy of residents to disagree is likely to increase trust, on the basis of which dialogue can proceed till a final decision and its implementation. This approach should help grasp the contextual factors that crucially affect the dynamics of communication and power in the policy process.

Second, flood risk mitigation options in participatory processes can be effectively elaborated by interfacing stakeholder preferences with expert knowledge, rather than by presenting a full-fledged picture and then asking for people's feedback.

Third, recognition of the diversity of priorities and views is a prerequisite for effective decision-making. A top-down, more "interventionist" approach is not detrimental in this respect if there is already a habit of informal involvement of the local community in decisionmaking. This of course does not reduce the importance of testing and implementing formal 
participatory approaches to address trade-offs and reach a compromise on risk mitigation options, especially when compared to traditional top/down decision-making processes. It is obvious that there is a direct relationship between the level of formality of a process and the "size" of an issue (territorial in our case, but other dimensions can be of course relevant to other sorts of problems) and of the affected groups. Informal participation is much easier when the community size is small. Yet nothing prevents carrying out a process through more "scaled down" informal phases (for example, at the level of neighborhoods), followed by more formalized "scaled up" phases. This is, for example, the logic of the "participatory budgeting" model (Wampler and Avritzer 2004; Sintomer et al. 2008). Yet besides any possible refinement in design, one has to recognize that participation is not a process that can be effectively activated from scratch and at will, but needs to be patiently constructed through reciprocal awareness and acquaintance, which means citizen involvement in and assumption of responsibility for territorial management in its broadest sense is a matter of continuous commitment.

\section{Acknowledgements}

This article draws on two different projects: the Integrated Project Floodsite (2004-2009; http://www.floodsite.net), Contract GOCE-CT-2004-505420 (European Community's Sixth Framework Programme), and the Coordination Action CapHaz-Net (2009-2012; http://caphaz-net.org/), Contract No. 227073 (European Community’s Seventh Framework Programme). The article reflects the authors' views and not those of the European Community. Neither the European Community nor any member of the Floodsite or CapHazNet Consortium is liable for any use of the information in this article. We thank all those who took part in the research as survey respondents, interviewees, workshop participants, or providers of information and for local support in the two case studies of Malborghetto- 
Valbruna and Vipiteno-Sterzing. We are also grateful to Bruna De Marchi, former Head of the Mass Emergencies Programme at the Institute of International Sociology of Gorizia (ISIG) and who is now at the Centre for the Study of the Sciences and the Humanities, University of Bergen. She coordinated the work of the ISIG team in the Floodsite project and provided advice to several phases of the CapHaz-Net project.

Anna Scolobig is researcher in the Climate Policy Group, at ETH-Swiss Federal Institute of Technology in Zürich. Her main research interests are in the social dimensions of environmental change, public participation in science for policy, human systems' response to disasters and social vulnerability, risk communication and governance. Before joining ETH she worked at the International Institute for Applied Systems Analysis in Vienna, the University of Trieste, and the Institute of International Sociology of Gorizia. She has been involved in a number of EC funded projects, in the 6th and 7th Framework Programme, all with an interdisciplinary vocation. Among her recent publications: Scolobig, A., De Marchi, B., Borga, M. 2012. “The Missing Link between Flood Risk Awareness and Preparedness: Findings from Case Studies in an Italian Alpine Region.” Natural Hazards 63(2): 499-520. Address: ETH-Swiss Federal Institute of Technology, Climate Policy Group, Department of Environmental Systems Science, Universitätstraße 16 CHN J72.2, 8092 Zürich, Switzerland. E-mail: anna.scolobig@usys.ethz.ch.

Luigi Pellizzoni is an associate professor in Sociology of the Environment at the Department of Political and Social Sciences of the University of Trieste. His research interests intersect two main areas: risk, environment, techno-science, and related policies and conflicts; participation and deliberative democracy. Among his recent publications: Neoliberalism and Technoscience: Critical Assessments (with Marja Ylönen, Ashgate, 2012). Address: 
University of Trieste, Department of Political and Social Sciences, Piazza Europa 1, 34127

Trieste, Italy. E-mail: pellizzonil@sp.units.it.

Chiara Bianchizza is a researcher and project manager at ISIG-Istituto di Sociologia Internazionale di Gorizia. Since 2010 she was a researcher at ISIG, where she worked for the FP7 project CapHaz-Net. Now she is a project coordinator for ISIG of EC-funded and locally based projects on stakeholders' involvement in participatory territorial management. She is in charge of project writing/management, as well as of research, on social capacity building for natural hazards, participation, social mechanisms of adaptation/mitigation to climate change, the role of perception in strengthening community participation and studies on social dynamics of sustainable development. Recent publications: Bianchizza C. and Frigerio S., "Domination of or Adaptation to Nature? A Lesson We Can Still Learn from the Vajont, Italian Journal of Engineering Geology and Environment-Book Series (6)

www.ijege.uniroma1.it. Address: ISIG-Institute of International Sociology of Gorizia, Italy, Via Mazzini, 13, 34170 Gorizia, Italy. E-mail: bianchizza@isig.it.

\section{References}

Aldred, Jonathan, and Michael Jacobs, M. 2000. "Citizens and Wetlands: Evaluating the Ely Citizens' Jury.” Ecological Economics 34(2): 217-232, doi: 10.1016/S09218009(00)00159-2.

Arnstein, Sherry. 1969. “A Ladder of Citizen Participation.” Journal of the American Institute of Planners 35: 216-224.

Beatley, Timothy. 1989. "Towards a Moral Philosophy of Natural Disaster Mitigation." International Journal of Mass Emergencies and Disasters 7(1): 5-32. 
Beatley, Timothy. 1999. Ethical Dilemmas in Hazard Mitigation Darby, PA: DIANE Publishing Co.

Becu, Nicolas, Andreas Neef, Pepijn Schreinemachers, and Chapika Sangkapitux. 2008. "Participatory Computer Simulation to Support Collective Decision-Making: Potential and Limits of Stakeholder Involvement." Land Use Policy 25(4): 498-509, doi: 10.1016/j.landusepol.2007.11.002.

Bianchizza, Chiara, Anna Scolobig, Luigi Pellizzoni, and Daniele Del Bianco. 2011. "2nd CapHaz-Net Regional Hazard Workshop: Social Capacity Building for Alpine Hazards.” EC Project CapHaz-Net Project Research Report. Gorizia: Institute of International Sociology of Gorizia, http://caphaznet.org/outcomesresults/CapHazNet_WP8_RHW-Alpine-Hazards.pdf. (accessed 11 August 2014).

Blaikie, Piers, Terry Cannon, Ian Davis, and Ben Wisner. 1994. At Risk: Natural Hazards, People's Vulnerability, and Disasters. London: Routledge.

Burby, Raymond. 1998. Cooperating with Nature: Confronting Natural Hazards with Landuse Planning for Sustainable Communities. Washington, DC: Joseph Henry Press.

Butler, Catherine, and Nick Pidgeon. 2011. 'From 'Flood Defence' to 'Flood Risk Management': Exploring Governance, Responsibility, and Blame.” Environment and Planning C: Government and Policy 29(3): 533-547.

Calzolari, Luigi. 2012. "Nubifragio in Val d'Isarco: Chiesto lo stato di emergenza." Il Giornale della Protezione Civile, 20 August. http://ilgiornaledellaprotezionecivile.it/index.html?act=src\&field=data_start\&ordering =DESC\&keyword=+Vipiteno\&field=data_start\&ordering=DESC (accessed 20 August 2012).

Carr, Gemma, Daniel Loucks, and Günter Blöschl. 2012. "Evaluating Participation in Water Resource Management: A Review.” Water Resources Research 48(11): 1-17. 
Cialdini, Robert. 2001. Influence: Science and Practice. New York: Harper-Collins.

Couzin, Iain, et al. 2011. "Uninformed Individuals Promote Democratic Consensus in Animal Groups.” Science 332(6062): 1578-1580, doi: 10.1126/science.1210280.

De Marchi, Bruna. 2003. "Public Participation and Risk Governance.” Science and Public Policy 30(3): 171-176, doi: 10.3152/147154303781780434.

De Marchi, Bruna, and Anna Scolobig. 2008. "Risk and Safety Dilemmas in Flood Prone Areas.” Mass Emergencies Programme Papers 08(2): 1-10.

De Marchi, Bruna, Anna Scolobig, Giovanni Delli Zotti, and Maura Del Zotto. 2007. "Risk Construction and Social Vulnerability in an Italian Alpine Region.” EC FLOODsite Project Research Report, Gorizia: Institute of International Sociology of Gorizia http://www.floodsite.net/html/partner_area/search_results3b.asp?docID=131 (accessed 11 August 2014).

Department for Environment and Rural Affairs (DEFRA). 2005. Making Space for Water: Developing a New Government Strategy for Flood and Coastal Erosion Risk Management in England: A Delivery Plan, Department for Environment. London: Food and Rural Affairs Defra. http://archive.defra.gov.uk/environment/flooding/documents/policy/strategy/strategyresponse1.pdf (accessed 11 August 2014).

Department for Environment and Rural Affairs (DEFRA). 2008. Consultation on Policy Options for Promoting Property-level Flood Protection and Resilience. London: Food and Rural Affairs Defra. http://www.environmentagency.gov.uk/static/documents/Research/property_2156986.pdf (accessed 15 June 2012).

Dieperink, Carel, Colin Green, Dries Hegger, Peter Driessen, Marloes Bakker, Marleen Van Rijswick, Ann Crabbe, and Kristina Ek. 2013. "Flood Risk Management in Europe: 
An Exploration of Governance Challenges (report no. D1.1.2).” EC STAR-FLOOD Project Research Report, Utrecht: STARFLOOD Consortium. http://www.starflood.eu/documents/2013/06/d1-1-2.pdf (accessed 11 August 2014). Dryzek, John. 2000. "Introduction: The Deliberative Turn in Democracy Theory.” In Deliberative Democracy and Beyond, ed. John Dryzek, pp. 1-25. Oxford: Oxford University Press.

Eckstein, Harry. 1975. "Case Study and Theory in Political Science.” In Handbook of Political Science, ed. Fred Greenstein, et al., pp. 18-35. Reading, MA: AddisonWesley.

European Commission (EC). 2000. "Directive 2000/60/EC Establishing a Framework for Community Action in the Field of Water Policy." Official Journal of the European Communities L 327 (European Commission, Brussels) http://eur-lex.europa.eu/ (accessed 11 August 2014).

European Commission (EC). 2007. "Directive 2007/60/EC on the Assessment and Management of Flood Risks." Official Journal of the European Communities L 288 (European Commission, Brussels) http://eur-lex.europa.eu/ (accessed 11 August 2014).

European Environment Agency (EEA). 2010. Mapping the Impacts of Natural Hazards and Technological Accidents in Europe-An Overview of the Last Decade, Technical Report no. 13/2010, IISN 1725-2237, (European Environment Agency, Luxembourg, Publications Office of the EU) http://www.eea.europa.eu/publications/mapping-theimpacts-of-natural (accessed 11 August 2014).

Few, Roger, Katrina Brown, and Emma Tompkins. 2007. "Public Participation and Climate Change Adaptation: Avoiding the Illusion of Inclusion." Climate Policy 7(1): 46-59, doi: 10.1080/14693062.2007.9685637. 
Fishkin, James, and Peter Laslett. eds. 2003. Debating Deliberative Democracy. Oxford: Blackwell.

Flyvbjerg, Bent. 2011. “Case Study.” In The Sage Handbook of Qualitative Research, ed. Norman Denzin, pp. 301-306, 4th Edition. Thousand Oaks, CA: Sage.

Fung, Archon, and Erik Wright, eds. 2003. Deepening Democracy: Institutional Innovations in Empowered Participatory Governance. London: Verso.

Gastil, John, and Peter Levine. 2005. The Deliberative Democracy Handbook: Strategies for Effective Civic Engagement in the $21^{\text {st }}$ Century. San Francisco, CA: Jossey-Bass.

Godschalk, David, Samuel Brody, and Raymond Burby. 2003. "Public Participation in Natural Hazard Mitigation Policy Formation: Challenges for Comprehensive Planning.” Journal of Environmental Planning and Management, 46(5): 733-754, doi: 10.1080/0964056032000138463.

Goodenough, William. 1970. Description and Comparison in Cultural Anthropology. Cambridge: Cambridge University Press.

Green, Colin, Carel Dieperink, Kristina Ek, Dries Hegger, Maria Pettersson, Sally Priest, and Sue Tapsell. 2013. "Flood Risk Management in Europe: The Flood Problem and Interventions.” (Report no D1.1.1), EC STAR-FLOOD Project Research Report, Utrecht: STARFLOOD Consortium. http://www.starflood.eu/documents/2013/06/d11-1.pdf (accessed 11 August 2014).

Gregory, Robin. 2002. “Incorporating Value Trade-Offs into Community-Based Environmental Risk Decisions.” Environmental Values 11(3): 461-488, doi: 10.3197/096327102129341181.

Harris, Marvin. 1980. Cultural Materialism: The Struggle for a Science of Culture. New York: Random House. 
Intergovernmental Panel on Climate Change (IPCC). 2012. Special Report on Managing the Risks of Extreme Events and Disasters to Advance Climate Change Adaptation (SREX). Intergovernmental Panel on Climate Change, http://www.ipccwg2.gov/SREX/images/uploads/SREX-All_FINAL.pdf (accessed 11 August 2014). Johnson, Clare, and Sally Priest. 2008. "Flood Risk Management in England: A Changing Landscape of Risk Responsibility.” International Journal of Water Resources Development 24(4): 513-525, doi: 10.1080/07900620801923146.

Junker, Berit, Matthias Buchecker, and Ulrike Muller-Boker. 2007. “Objectives of Public Participation: Which Actors Should be Involved in the Decision-Making for River Restoration?" Water Resources Research 43(10): 1-11, W10438, doi: 10.1029/2006WR005584.

Kallis, Giorgios, Dionisia Hatzilacou, Alexandra Mexa, Harry Coccossis, and Eleni Svoronou. 2009. "Beyond the Manual: Practicing Deliberative Visioning in a Greek Island." Ecological Economics 68(4): 979-989.

Kuhlicke, Christian, Annett Steinführer, Chloe Begg, and Jochen Luther. 2012. "Toward More Resilient Societies in the Field of Natural Hazards: CapHaz-Net's Lessons Learnt." EC CapHaz-Net Project Research Report. Leipzig: Helmholtz Centre for Environmental Research. http://caphaz-net.org/outcomes-results/CapHazNet_WP10_Lessons-learnt.pdf (accessed 11 August 2014).

Kuhlicke, Christian, and Annett Steinführer. 2010. "Social Capacity Building for Natural Hazards. A Conceptual Frame.” EC CapHaz-Net Project Research Report. Leipzig: Helmholtz Centre for Environmental Research. http://caphaz-net.org/outcomesresults/CapHaz-Net_WP1_Conceptual_frame.pdf (accessed 11 August 2014).

Lofstedt, Ragnar. 2004. "Risk Communication and Management in the Twenty First Century.” International Public Management Journal 7(3): 335-346. 
McDaniels, Timothy, Robin Gregory, and Daryl Fields. 1999. "Democratizing Risk Management: Successful Public Involvement in Local Water Management Decisions.” Risk Analysis 19(3): 497-510, doi: 0272-4332/99/0600-0497\$16.00/1.

Messner, Frank, Oliver Zwirner, and Matthias Karkuschke. 2006. "Participation in Multicriteria Decision Support For the Resolution of a Water Allocation Problem in the Spree River Basin.” Land Use Policy 23(1): 63-75.

Paneque Salgado, Pilar, Serafin Corral-Quintana, Angela Guimaraes Pereira, Leandro Del Moral Ituarte, and Belen Pedregal Mateos. 2009. "Participative Multi-criteria Analysis for the Evaluation of Water Governance Alternatives: A Case in the Costa del Sol (Malaga).” Ecological Economics 68(4): 990-1005, doi: 10.1016/j.ecolecon.2006.11.008.

Parkinson, John. 2006. Deliberating in the Real World: Problems of Legitimacy in Deliberative Democracy. Oxford: Oxford University Press.

Pellizzoni, Luigi. ed. 2007. Democrazia Locale: Apprendere dall'Esperienza. Gorizia: Institute of International Sociology Gorizia.

Pellizzoni, Luigi. 2010. “Environmental Knowledge and Deliberative Democracy.” In Environmental Sociology: European Perspectives and Interdisciplinary Challenges, ed. Matthias Gross and Harald Heinrichs, pp. 159-185. Berlin: Springer.

Pellizzoni, Luigi. 2013. “Une Idée Sur Le Déclin? Evaluer la Nouvelle Critique de la Délibération Publique.” Participations 2 (special issue on Critique de la Participation et Gouvernementalité): 87-118.

Penning-Rowsell, Edmund, and Joanna Pardoe. 2012. "Who Benefits and Who Loses From Flood Risk Reduction?” Environment and Planning C: Government and Policy 30(3): 448-466, doi: 10.1068/c10208. 
Pike, Kenneth. 1967. Language in Relation to a Unified Theory of Structure of Human Behavior. The Hague: Mouton.

Renn, Ortwin. 2008. Risk Governance: Coping with Uncertainty in a Complex World. London: Earthscan.

Rowe, Gene, and Lynn Frewer. J. 2000. "Public Participation Methods: A Framework for Evaluation," Science, Technology \& Human Values 25(1): 3-29, doi: $10.1177 / 016224390002500101$.

Scolobig, Anna, JoAnne Bayer, Leonardo Cascini, and Settimio Ferlisi. 2011. "Design and Testing: A Risk Communication Strategy and a Deliberative Process for Choosing a Set of Mitigation and Prevention Measures." EC SafeLand Project Research Report. Vienna: International Institute for Applied Systems Analysis. http://www.safelandfp7.eu/results/Documents/D5.7.pdf (accessed 11 August 2014).

Scolobig, Anna, Vanesa Castan-Broto, and Aiora Zabala. 2008. "Integrating Multiple Perspectives in Social Multicriteria Evaluation of Flood Mitigation Alternatives: The Case of Malborghetto-Valbruna." Environment and Planning C: Government and Policy 26(6): 1143-1161.

Sintomer, Yves, Carsten Herzberg, and Anja Röcke. 2008. "Participatory Budgeting in Europe: Potentials and Challenges." International Journal of Urban and Regional Research 32(1): 164-178.

Stake, Robert E. 1995. The Art of Case Study Research. Thousand Oaks, CA: Sage.

Stirling, Andrew. 2005. “Opening up or Closing Down: Analysis, Participation and Power in the Social Appraisal of Technology." In Science and Citizens, ed. Ian Scoones and Brian Wynne, pp.218-232. London: Zed Books.

Yin, Robert K. 1989. Case Study Research: Design and Methods. Newbury Park, CA: Sage. 
Walker, Gordon, Rebecca Whittle, William Medd, and Neil Watson. 2010. "Risk Governance and Natural Hazards.” EC CapHaz-Net Project Research Report. Lancaster: Lancaster University. http://caphaz-net.org/outcomes-results/CapHaz-Net_WP2_RiskGovernance.pdf (accessed 11 August 2014).

Wampler, Brian, and Leonardo Avritzer. 2004. "Participatory Publics: Civil Society and New Institutions in Democratic Brazil.” Comparative Politics 36(3): 291-312, doi: $10.2307 / 4150132$.

World Metereological Organisation (WMO). 2013. The Global Climate 2001-2010: A

Decade of Climate Extremes, Summary Report. Geneva: World Meteorological Organisation. http://library.wmo.int/opac/index.php?lvl=notice_display\&id=15110. (accessed 11 August 2014)

Wynne, Brian. 1992. "Misunderstood Misunderstandings: Social Identities and Public Uptake of Science." Public Understanding of Science 1(3): 281-304.

\section{Notes}

1. Flood risk can be reduced in many different ways. Settlement relocation or prohibition is one among many options including construction of protection works, adoption of restrictive building regulations in risk-prone areas, development of monitoring and warning systems, preparation and updating of emergency plans, awareness raising campaigns, risk education activities and many other mitigation and adaptation measures that are often combined in the design of a risk mitigation plan (Merz et al. 2010; Blöschl et al. 2013).

2. The Hyogo Framework offers guiding principles, priorities for action and practical means for achieving disaster resilience for vulnerable communities. Its goal is to substantially reduce disaster losses in lives and in the social, economic, and environmental assets of communities and countries. The initiative started in January 2005 when 168 Governments adopted a ten- 
year plan to make the world safer from natural hazards at the World Conference on Disaster Reduction, held in Kobe, Hyogo, Japan. See http://www.preventionweb.net/english/hyogo/. 3. The case study approach is a widely applied method in a range of disciplines such as sociology, political science, anthropology, economics, geography and medical science. In recent decades the method gained popularity in testing hypotheses and identifying patterns, for example in decision-making (Yin 1989; Stake 1995; Flyvbjerg 2011). Another strength is the depth of analysis as it pertains to the local context, origins of a phenomenon, and stakeholder contextual knowledge. Improved capacity of linking causes and outcomes and fostering new hypotheses and new research questions are additional qualities often highlighted. The method also has obvious weaknesses that we acknowledge from to outset: it is a qualitative method and does not produce statistically significant data. 